\title{
Theoretical Modeling Approaches to Spur Gear Strength Analysis by FEM
}

\author{
Jianrong Zhang ${ }^{\mathrm{a}}$, Shuangxue $\mathrm{Fu}^{\mathrm{b}}$ \\ Guangzhou Civil Aviation College, Guangzhou, 510403, China \\ acaacfsx@163.com, bfushuangxue@caac.net
}

Keywords: Spur Gear, Strength Analysis, FEM.

\begin{abstract}
Gear strength analysis is important to gear drive design, and its calculating accuracy is mainly decided by gear model. Several factors influencing the spur gear model building accuracy by finite element method (FEM) are presented, including geometric model and boundary, loading position and load types. The research includes: (1)A geometric model of spur gear is built. (2)Based on the gear model, geometric boundary of analytic model is determined. (3) The loading point of bending strength calculation is studied. (4)Static effective load and dynamic contact load effects on root stresses and tooth deformation are researched. The results show that tooth profile, geometric boundary, loading position and effective load, are the key factors of calculating accuracy and gear strength analysis. The reasonable FEM modeling methods can improve the calculating precision.
\end{abstract}

\section{Introduction}

With the development of high-speed, heavy-load, high-precision and low-noise gear transmission, refined calculation of gear strength is demanded. FEM is widely used in modern gear drive design.

For bending strength calculation, Wilcox [1], Charber [2] and Wei [3] analyzed root stress and tooth deformation by FEM with 2-D single tooth model. Chang[4], Von Eiff [5] and Bibel [6] began to explore the effects of tooth profile, boundary condition, grid density on tooth stress with 2-D multi-teeth model. Filliz [7] studied the effects of contact ratio, tooth fillet radius, module on tooth stress, using three conditions (i.e. point-load, distribute load and simulated contact). Alexander [8] optimized fillet curve in order to decrease root bending stress by FEM.

For contact strength calculation, Corry [9] counted the teeth compliance and contact stress by programming. Coy [10] found more calculated errors for the deflection of meshing area was caused, if distribute load was simplified to point load. Refaat [11] used variational inequalities and contact analysis by FEM to count contact and bending stress. Fang [12] resolved the flexibility tensors of all nodes on working surfaces and 3-D continual elastic contact problem with friction, by means of differential geometry and contact mechanics. Lee [13] analyzed the dynamic contact effects between rotating spur gears by FEM and multi-body dynamics techniques. Li [14] studied contact strength and bending strength of a pair of spur gears with machining errors, assembly errors and tooth modifications by FEM.

There are several limitations in the above studies: (1) Simplification of root fillet curves in tooth geometric model causes counting errors. (2) Geometric boundary (radius thickness and span teeth numbers) of analytic model isn't studied systematically. (3)Loading boundary conditions, especially for loading position and load types, et al, require to explore thoroughly.

Based on generating principle, coordinate conversion and the studies of geometric boundary and loading position in documents [15 17], theoretical gear model for FEM is advanced in this article, considering the tooth profile, geometric boundary, effective load and its boundary. Compared with the others, this modeling methods are proved correct.

\section{Geometrical model of spur gear tooth}

Gear parameters are given in Table 1 . The transmission ratio of two meshing gears is 1 , and the 
gear and pinion are 7 grade precision. Tooth profile error and the deformation of axis and gearbox are ignored. Effect of shearing on gear strength is considered for short and thick tooth. The material of gear and pinion is $45 \#$ steel, its property parameters shown in Table 2. Rotation speed $n_{1}$ is $100 \mathrm{r} / \mathrm{min}$ and transmission power $P$ is $5.5 \mathrm{kw}$.

Table 1 Gear parameters

\begin{tabular}{cccccc}
\hline $\begin{array}{c}\text { Tooth } \\
\text { Nummber }\end{array}$ & $\begin{array}{c}\text { Pressure } \\
\text { Angle }\end{array}$ & Modulus & $\begin{array}{c}\text { Tooth } \\
\text { Width }\end{array}$ & $\begin{array}{c}\text { Axis } \\
\text { Diameter }\end{array}$ & $\begin{array}{c}\text { Addendum } \\
\text { Coefficient }\end{array}$ \\
\hline $\mathrm{z}$ & $\alpha /\left(^{\circ}\right)$ & $\mathrm{m} / \mathrm{mm}$ & $\mathrm{b} / \mathrm{mm}$ & $\mathrm{d}_{0} / \mathrm{mm}$ & $\mathrm{x} / \mathrm{mm}$ \\
$30 / 30$ & 20 & 6 & 80 & 50 & 0 \\
\hline
\end{tabular}

\begin{tabular}{|c|c|c|c|c|}
\hline Material & $\begin{array}{c}\text { Elastic } \\
\text { Modulus }\end{array}$ & $\begin{array}{l}\text { Shearing } \\
\text { Modulus }\end{array}$ & $\begin{array}{l}\text { Poisson's } \\
\text { Ratio }\end{array}$ & Density \\
\hline & $E / G P a$ & $G / G P a$ & $v$ & $\rho / \mathrm{kg} \cdot \mathrm{m}^{-3}$ \\
\hline
\end{tabular}

Tooth profile is processed by standard hob with no protuberance type and pressure angle $20^{\circ}$, and the standard hob is shown in Fig.1. As shown in Fig.2,The involute part of tooth profile is generated by the straight line section of the hob. The fillet curve part is generated by the round corner of the hob, and the part of the dedendum arc generated by the addendum flatform of the hob.

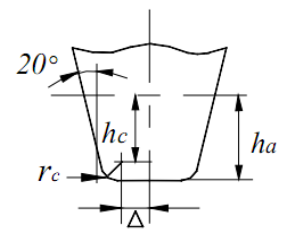

Fig. 1 Tooth profile of hob

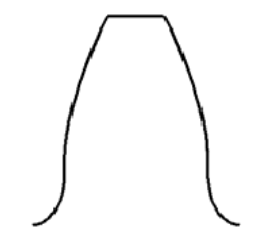

Fig.2 Tooth shape of gear

The coordinates of the points on the involute part may be given as

$$
x=r_{i} \sin \eta_{i}, y=r_{i} \cos \eta_{i}
$$

Where $r_{i}$ is the radius of any point on the tooth profile. $\eta_{i}$ is the pressure angle of the point, see Fig.3.

$$
\eta_{i}=\frac{\pi}{2 z}-\left(i n v \alpha_{i}-i n v \alpha\right)
$$

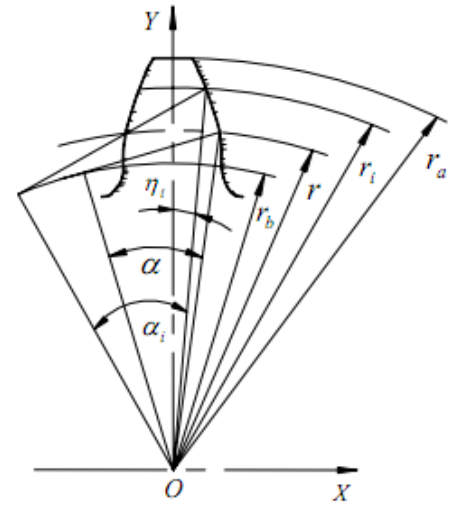

Fig.3 Tooth profile

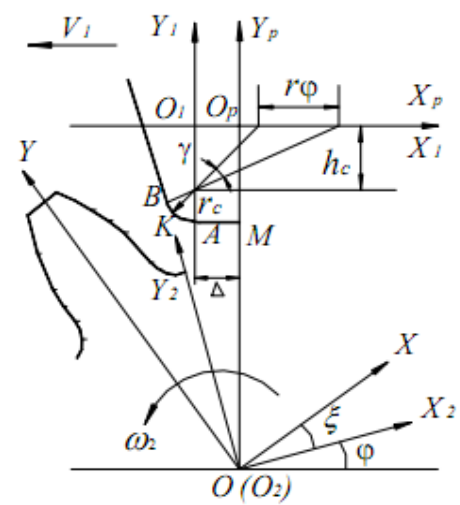

Fig.4 Coordinate Conversion

And transition curve equations can be expressed as

$$
\begin{aligned}
& X_{f}=\left(r-h_{c}\right) \sin (\xi+\theta)-r \theta \cos (\xi+\theta)-r_{c}\left(h_{c}^{2}+r^{2} \theta^{2}\right)^{-0.5}\left[h_{c} \sin (\xi+\theta)+r \theta \cos (\xi+\theta)\right] \\
& Y_{f}=\left(r-h_{c}\right) \cos (\xi+\theta)-r \theta \sin (\xi+\theta)-r_{c}\left(h_{c}^{2}+r^{2} \theta^{2}\right)^{-0.5}\left[h_{c} \cos (\xi+\theta)-r \theta \sin (\xi+\theta)\right]
\end{aligned}
$$

$r, \quad r_{c}$ is the pitch circle radius of gear and the radius of the round corner of the hob, respectively $h_{c}$ is the distance of the pitch line and the center of the round corner of the hob. $\gamma$ is the rotating angle of the round corner, range in 0 to 70 degree. $\xi, \theta$ are shown in Fig.4. 
According to Eqs. (1),(2) and (3),the exact position coordinates of the points on tooth profile are solved in MATLAB and written into a full-text date file. The file is imported as APDL program, and then theoretical tooth profile is attained in ANSYS. The gear body is shown in Fig.5.

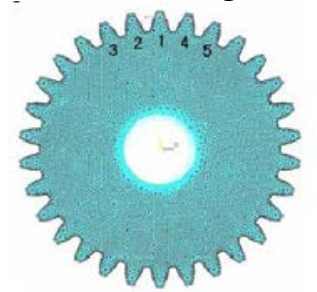

Fig.5 Geometric model of spur gear

\section{Geometric boundary of the finite element model of spur gear}

Plane element is chosen in order to save computing time, without influencing the results. The effects of radius thickness and span teeth numbers on load capacity of tooth are analyzed. In Table 3, three part models are divided from the whole gear model, with the same element type and grid density. Both sides and axis hole of part models are with fixed constrains. For the whole model, the axis hole is with fixed constrains only. The difference ratio of counting results between 3-teeth model and the whole one is 3.62\%, 5-teeth model and the whole one being $0.11 \%$ only, but larger counting errors exist in 1-tooth model and the whole one. Zero displacement constrains are loaded on both sides of the analytical model, stead of "small displacement" situated at the same position for the whole model, when tooth numbers are equal to 5 or more.

\begin{tabular}{|c|c|c|c|c|}
\hline Teeth & Numbers & \multicolumn{2}{|c|}{$\begin{array}{c}\text { Maximum Root Stresses } \\
(\mathrm{MPa})\end{array}$} & \multirow{2}{*}{$\begin{array}{c}\text { Difference } \\
-\end{array}$} \\
\hline & \multirow{3}{*}{30} & $\sigma_{c \text { max }}$ & 43.540 & \\
\hline & & $\sigma_{t \max }$ & 36.430 & - \\
\hline & & $\sigma_{c \max }$ & 43.563 & 0.05 \\
\hline & \multirow[t]{2}{*}{5} & $\sigma_{t_{\max }}$ & 36.470 & 0.11 \\
\hline & & $\sigma_{c \max }$ & 44.790 & 2.87 \\
\hline & \multirow[t]{2}{*}{3} & $\sigma_{t_{\max }}$ & 37.750 & 3.62 \\
\hline & & $\sigma_{c \max }$ & 46.800 & 7.49 \\
\hline & 1 & $\sigma_{t \text { max }}$ & 39.050 & 7.19 \\
\hline
\end{tabular}

On basis of 5-teeth finite element model (seen in Fig.6), the variable rules existing in the ratio of radius-modulus(i.e. $\beta=t / m$ ) and root stresses or tooth deformation are discussed. Where $t$ is the distance of counting node and the dedendum, $m$ is modulus. The conclusions can be drawn from Figs. 7 and 8:

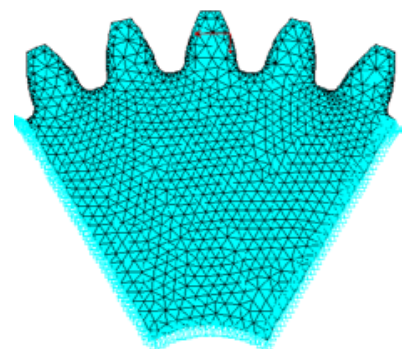

Fig.6 5-teeth finite element model 


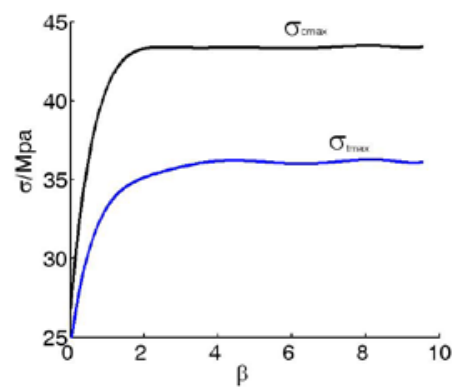

Fig.7 Maximum root stress and ratio of thickness-modulus $\beta$

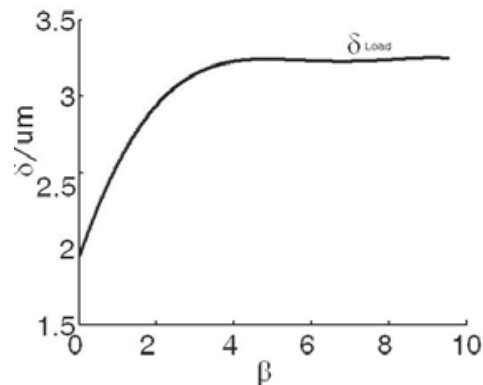

Fig.8 Compliance of loaded point and ratio of thickness-modulus $\beta$

1) $\beta<2$, maximum root stress decreases intensely with the decrease of $\beta$, meaning to the obvious effect of radius thickness on maximum root stress. $2 \leq \beta<4$, maximum root stress increases slowly with the increase of $\beta .4 \leq \beta$, maximum root stress hardly varies with the increase of $\beta$, meaning to being a stable "platform stage".

2) $\beta<4$, tooth deformation decreases rapidly with the decrease of $\beta$, i.e. the obvious effect of radius thickness on tooth deformation. $4 \leq \beta$, tooth deformation hardly varies with the increase of $\beta$, i.e. being as a stable "platform stage".

3) $\beta<2$, maximum root compressive stress is acuter to $\beta$ than tensile stress. $2 \leq \beta$, the difference between compressive and tensile stress is stable, but compressive stress is easy to stabilize a constant level.

The theoretical rage of "effective boundary" in this case can be determined as: span teeth numbers $C_{Z} \geq 5$, ratio of ratio of radius-modulus $\beta \geq 4$.

\section{Loading position for spur gear strength analysis}

Andrews[18] found loading position influenced on maximum root stress intensely, after studying the rule between maximum compressive or tensile and loading position. Method for determining the loading position of bending strength analysis is studied as follows.

In the standards of ISO and GB/T 3480-1997, loading position for bending strength calculation is defined as two kinds: 1 ) the whole force loaded at the highest point of single tooth contact(HPSTC). 2) the whole force loaded at the tip of the tooth(TT). After the methods of mapping function, numerical integration and FEM used, the counting result of bending strength tends more accurate. The loading position is TT in mapping function model. Cornell [20] calculated the tooth compliance and root stress by numerical integration, as loading position at HPSTC. Eiff [5] studied the effects of tooth shape on root stress by FEM, as loading position at TT. The formulas of calculating root stress built by FEM, Chabert[2] and Filiz [7] didn't point out the exact loading position clearly.

There are main limitations in the above studies on bending strength analysis as follows. 1) The analytic models were built on basis of theoretical gear drive, without system errors and teeth flexibility. 2) The accurate judgment about maximum root stress and loading position wasn't given. Considering system errors of gear drive and teeth synthetic flexibility, the loading point for bending strength analysis was explored and the relative rule of loading position and maximum root 
stress was given as (in paper[16])

$$
f_{\text {pbeqv }}<\min \left\{\left|\left(q_{A 1}+q_{A 2}\right) P_{A}\right|,\left|\left(q_{B 1}+q_{B 2}\right) P_{B}\right|\right\}
$$

Where $f_{\text {pbeqv }}$ is effective basic pitch. $P_{A}, P_{B}$ are normal force per unit length of the mating points $\mathrm{A}$ and $\mathrm{B}$ respectively. $q_{\mathrm{A} 1}, q_{\mathrm{A} 2}$ are the teeth flexibility of pinion and gear at mating point A respectively. $q_{B 1}, q_{B 2}$ are the teeth flexibility of pinion and gear at mating point $\mathrm{B}$ respectively. Based on the rule, following results can be attained. 1) At 7 or above 7 level grade, false meshing of

one pair of gear teeth doesn't exist and the loading position should be determined at HPSTC. 2) Otherwise false meshing will appear and the whole force should be loaded at TT when bending strength counted.

To testify the above rule correct, simulation is carried in two cases, i.e. loading position being at HPSTC and TT, see in Figs. 9 (a) and (b). The counting results are compared with the empirical formulas in papers [2],[7],[21] and the standards of JGMA. To the gear at 7 level grade, it shows in Table 4 that the counting result is more reliable when loading position situated in HPSTC. The result is obviously larger when loading position being at TT.

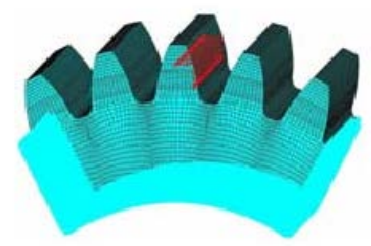

(a)

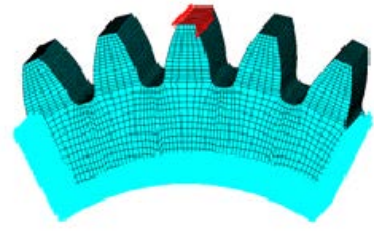

(b)

Fig.9 Loading position situated in HPSTC and TT

Table 4 Maximum root tensile stress $(\mathrm{MPa})$

\begin{tabular}{cccccc}
\hline TT & HPSTC & Charbert & Niemann & Fillize & JGMA \\
\hline 43.071 & 33.513 & 32.246 & 32.968 & 33.664 & 33.306 \\
\hline
\end{tabular}

\section{Effects of load type on spur gear strength}

Tooth profile is the curved face of variable curvature with contact interface of complex conjugate, and load is important influence on the solution accuracy in counting gear strength. It is necessary to research the effects of load types on calculating results, when gear strength analysis is simulated under different operating conditions. Based on the theoretical geometric model, effective loads on meshing teeth are studied. The influence of load types on counting solution is analyzed, due to two typical operating conditions, i.e. static load and dynamic contact.

Gear strength analysis of static mechanics or low-speed gear drive belongs to small deformation problem. The type of static mechanics can be two kinds, i.e. effective static load and static contact. The effective static load includes point load and linear distribute load. As the most typical problem of effective static load, the load type of static analysis is linear distribute load in this section, see in Fig.9.

Dynamic contact analysis of gear drive can simulate continuous meshing process and analyze root stress and tooth deformation of multi-teeth engaging. The dynamic contact behavior of teeth meshing is a high nonlinear problem, which can be dynamically simulate the variable rules of stress distribution and teeth deformation. The analytic gear model of dynamic contact is shown in Fig.10. 


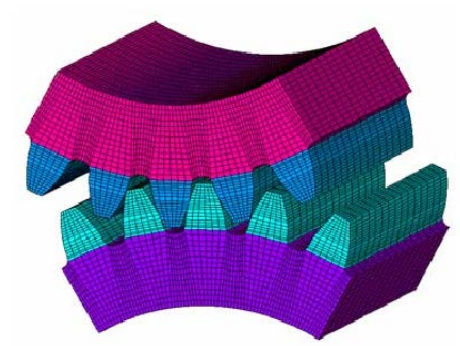

Fig.10 Dynamic contact model of gear teeth

The stress nephogams under linear distribute load is in accordance with the one under dynamic contact load, see in Figs. 11 and 12. The analytic results from static linear distribute load and dynamic contact are shown in Table 5. Due to dynamic effects, the result of dynamic contact analysis is bigger as rate of $10 \%$ than static load. Considering the total deformation including bending, shear, local compression and deflection of gear body, the deformation from dynamic contact analysis is bigger than one by static load. The simulation results of two kinds of load types response different operating statuses, which are in accordance with real working conditions.

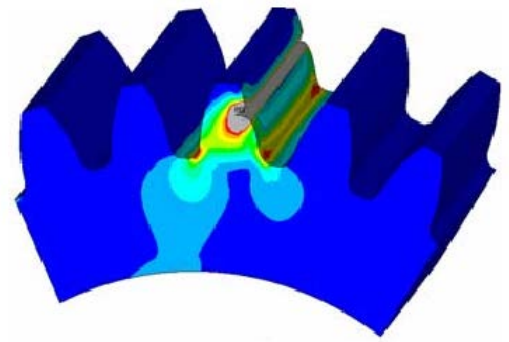

Fig.11 Stress nephogram of gear under linear distribute load

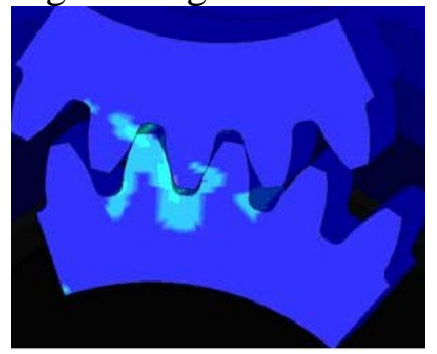

Fig.12 Stress nephogram of gear under dynamic contact load

Table 5 Root stressed of gear strength from linear distribute load and dynamic contact analysis

\begin{tabular}{cccc}
\hline Load type & $\begin{array}{c}\text { Comparative } \\
\text { items }\end{array}$ & $\begin{array}{c}\text { Linear } \\
\text { distribute }\end{array}$ & $\begin{array}{c}\text { Dynamic } \\
\text { contact }\end{array}$ \\
\hline $\begin{array}{c}\text { Compressive } \\
\text { stress }\end{array}$ & $\sigma_{c \max }(M P a)$ & 32.662 & 35.981 \\
$\begin{array}{c}\text { Tensile } \\
\text { stress }\end{array}$ & $\sigma_{t \max }(M P a)$ & 39.067 & 42.950 \\
Deformation & $\delta(u m)$ & 3.201 & 3.378 \\
\hline
\end{tabular}

\section{Summary}

(1) To improve the accuracy of gear strength analysis, the method for building theoretical geometric model of gear, based on generating principle and compositely modeling with MATLAB and APDL, is advanced.

(2)Reasonable geometric boundary of the model is determined by error limitation to maximum root stress and teeth compliance.

(3)The rule of judging loading point of bending strength analysis is studied, which system errors of gear drive and teeth synthetic flexibility considered.

(4)According to the corresponding relationship between operating statuses and load types, the rational choice of loads and analytical types can response more accurately the different mating statuses. 
Improved model for gear strength analysis by FEM, can improve the accuracy and reliability of model, and heighten the level of design and manufacture of gear drive.

\section{Acknowledgments}

The authors gratefully acknowledge the support of project of Guangdong province to cultivate outstanding young teachers in colleges and universities (YQ2014178) and by associate professor Shuangxue Fu who is the corresponding author of this paper.

\section{References}

[1] Wilcox L, Colman W,1973, “Application of finite elements to the analysis of gear tooth stress”, ASME Journal Engineering for Industry, 95(4), pp.1139-1148

[2] Chabert G, Dang T T, Mathis R,1974, “An evaluation of stresses and deflection of spur gear teeth under strain”,ASME Journal of Engineering for Industry, 96(1):85-93

[3] Wei R Z, Zhang Y Z, et al,1980, “Calculation of tooth compliance for spur gear”, Gear, 3(4), pp.1-8

[4] Chang S H, Huston R L, Coy J J,1983, “A finite element stress analysis of spur gears including fillet radii and rim thickness effects”, ASME Journal of Mechanisms, Transmissions, and Automation in Design, 105(3), pp.327-330

[5] Von Eiff H, Hirschmann K H, Lechner G, 1990, "Influence of gear tooth geometry on tooth stress of external and internal gears”, ASME Journal of Mechanical Design, 112(4), pp.575-583

[6] Bibel G D, Reddy S K, Savage M,1994, “Effects of rim thickness on spur gear bending stress”, ASME Journal of Mechanical Design, 116(12), pp.1157-1162

[7] Huseyin Filiz I, Eyercioglu O, 1995, "Evaluation of gear tooth stresses by finite element method”, ASME Journal of Engineering for Industry, 117(5), pp. 232-239

[8] Alexander L K, Shekhtman Y V, 2003, “Direct gear design: bending stress minimization”, Gear Technology, (9/10), pp.44-47

[9] Conry T F, Seireg A, 1973, "Mathematical programming technique for the evaluation of load distribution and optimal modification for gear systems", ASME Journal of Engineering for Industry,

95(11), pp.1115-1122

[10] Coy J J, Hu-Chih Chao C, 1982, “A method of selecting grid size to account for Hertz deformation in finite element analysis of spur gears”, Journal of Mechanical Design, 104(10), pp.759-765

[11] Refaat M H, Meguid S A, 1995, “On the contact stress analysis of spur gears using variational inequalities”, Computers and Structures, 57(5), pp.871-882

[12] Fang Z D, Yang H B, 1999. "Continual elastic contact analysis of gear teeth with friction by using programming method”, Chinese Journal of Mechanical Engineering, 35(6), pp.98-101

[13] Lee K, 2001, “Analysis of the dynamic contact between rotating spur gears by finite element and multi-body dynamics”, Proceedings Institution of Mechanical Engineers, Part C, 215, pp.423-434

[14] Li S T, 2007, "Finite element analyses for contact strength and bending strength of a pair of spur gears with machining errors, assembly errors and tooth modifications", Mechanism and Machine Theory, 42(1), pp. 88-114 
[15] Zhou C J, Tang J Y, Zhong Z H, et al, 2005, "Research on Boundary of Exact Modeling of Gear by FEM”, China Mechanical Engineering, 16 (22) , pp. 2044-2049

[16] Zhou C J, Zhong Z H, Tang J Y, 2007, "Research on the loading point of bending strength calculation based on gear error and flexibility”, Journal of Hunan University(Natural Sciences), 34(7), pp.35-38.

[17] Tang J Y, Zhou C J, Wu Y X, 2004,“ Method for Exact Modeling of the Bending of Spur Gear Teeth by FEM”, Mechanical Science and Technology, 23(10), pp.1146-1150

[18] Andrews J D, 1991, “A finite element analysis of bending stresses included in external and internal involutes spur gear”, Journal of Strain Analysis, 26(3), pp.153-163

[19] Cardou A, Tordion G V, 1981, "Numerical implementation of complex potentials for gear tooth stress analysis”, ASME Journal of Engineering for Industry, 103(2), pp.460-465

[20] Cornell R W, 1981, “Compliance and stress sensitivity of spur gear teeth”, ASME Journal of Mechanical Design, 103(4), pp.447-459

[21] G. Niemann, 1965, Maschinenelemente, band II [M]. Getriebe, Springer Verlag 